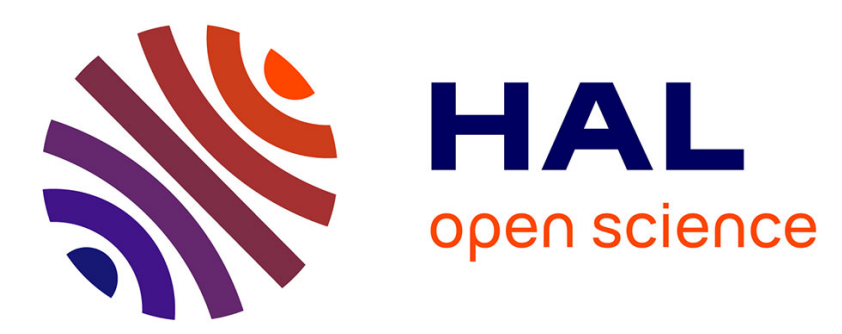

\title{
The Dislocation-Enhanced Finkelshtain-Rosin Effect (DEFRE) in Austenitic Steels
}

\author{
I. Golovin, S. Golovin
}

\section{To cite this version:}

I. Golovin, S. Golovin. The Dislocation-Enhanced Finkelshtain-Rosin Effect (DEFRE) in Austenitic Steels. Journal de Physique IV Proceedings, 1996, 06 (C8), pp.C8-143-C8-146. 10.1051/jp4:1996829 . jpa-00254637

\section{HAL Id: jpa-00254637 https://hal.science/jpa-00254637}

Submitted on 1 Jan 1996

HAL is a multi-disciplinary open access archive for the deposit and dissemination of scientific research documents, whether they are published or not. The documents may come from teaching and research institutions in France or abroad, or from public or private research centers.
L'archive ouverte pluridisciplinaire HAL, est destinée au dépôt et à la diffusion de documents scientifiques de niveau recherche, publiés ou non, émanant des établissements d'enseignement et de recherche français ou étrangers, des laboratoires publics ou privés. 


\title{
The Dislocation-Enhanced Finkelshtain-Rosin Effect (DEFRE) in Austenitic Steels
}

\author{
I.S. Golovin and S.A. Golovin* \\ State Aviation Technology University, Met. Sci. Dep., Petrovka 27, Moscow 103767, Russia \\ * State University, Mat. Sci. Dep., Lenin av. 92, Tula 300600, Russia
}

\begin{abstract}
A systematic study of the influence of plastic deformation and low temperature ageing on the carbon Dislocation - Enhanced Finkelshtain - Rosin Effect (DEFRE/C) in austenitic alloys of Fe-Ni, Fe-Ni-Mo, $\mathrm{Fe}-\mathrm{Mn}$-Al and $\mathrm{Fe}-\mathrm{Cr}-\mathrm{Ni}$ systems with different carbon content is reported. The experiments prove that after plastic deformation at room temperature the FR effect is transformed into DEFRE/C, with both phenomena occurring at the same temperature. The influence of plastic deformation, carbon and alloying elements concentration on DEFRE/C in deformed austenitic steels is reported.
\end{abstract}

\section{INTRODUCTION}

The mechanical response on the dynamic redistribution of interstitial atoms in austenite under the applied cyclic stress is the IF peak around $250-300^{\circ} \mathrm{C}$ ( $\mathrm{f} \sim 1 \mathrm{~Hz}$ ) established by Finkelshtein and Rosin (FR peak) [1]. Single interstitial does not produce any IF peak in f.c.c. metals. The FR peak is connected with the reorientation of pairs of interstitial atoms in the field of applied cyclic stress and the peak height has more complicated concentration dependence on interstitials $(C, N)$ content. Relative simplicity of Snoek peak mechanisms has determined its quick theoretical development and a wide experimental usage [2]. In particular, the plastic deformation decreases the Snoek peak height due to the redistribution of interstitial atoms between solid solution and "fresh" dislocations and to the appearance of the so-called Snoek-Köster peak. The dislocationenhanced Snoek effect (DESE) was studied in b.c.c. crystals by Ogurtani and Seeger (results were generalized in [3]) and was experimentally checked for pure iron by Magalas and co-authors [4]. The same approach has been never checked for austenitic alloys. Nevertheless it was found out as early as in 1965 that the plastic deformation of austenitic steels leads to the appearance of strain induced IF peak in the vicinity of temperature range of FR peak [5]. The experimental study and the attempt of a computer separation of FR and strain-induced IF peak in some Fe-Ni, Fe-Ni-Mo, $\mathrm{Fe}-\mathrm{Cr}-\mathrm{Ni}$ and $\mathrm{Fe}-\mathrm{Mn}-\mathrm{Al}$ alloys were recently reported in [6]. Finally, the attempt to explain the origin of this effect in austenitic alloys (named DEFRE) is done in the present paper.

\section{EXPERIMENTAL PROCEDURE}

Temperature dependent internal friction (TDIF) has been studied for the austenitic $\mathrm{Fe}-\mathrm{Ni}, \mathrm{Fe}-\mathrm{Ni}$ $\mathrm{Mo}, \mathrm{Fe}-\mathrm{Cr}-\mathrm{Ni}$ and $\mathrm{Fe}-\mathrm{Mn}-\mathrm{Al}$ alloys. The chemical compositions for alloys investigated are given in Table 1.

Table 1. Chemical compositions of austenitic alloys.

\begin{tabular}{|c|c|c|c|c|c|c|c|}
\hline System & $\mathrm{C}$ & $\mathrm{N}$ & $\mathrm{Ni}$ & Mo & $\mathrm{Cr}$ & $\mathrm{Mn}$ & Al \\
\hline $\mathrm{Fe}-24 \% \mathrm{Ni} 4 \% \mathrm{MO}$ & 0.088 & $<0.002$ & 25.9 & 4.4 & $\cdots$ & $-\cdots$ & 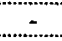 \\
\hline $\mathrm{Fe}-42 \% \mathrm{Ni}$ & 0.021 & $<0.002$ & 42 & - & - & - & $\because$ \\
\hline $\mathrm{Fe}-18 \% \mathrm{Cr}-9 \% \mathrm{Ni}$ & 0.12 & - & 8.75 & - & 17.44 & 1.46 & - \\
\hline $\mathrm{Fe}-17 \% \mathrm{Mn}-3 \% \mathrm{Al}$ & 0.45 & $\because$ & - & & 0.24 & 17.45 & 2.76 \\
\hline
\end{tabular}

The wire samples $(\varnothing=0.8 \mathrm{~mm})$ have been used for IF measurements. The samples have been water quenched after $5.10 \mathrm{~min}$ annealing at temperatures of $1075^{\circ} \mathrm{C}$ (for $\mathrm{Fe}-18 \% \mathrm{Cr}-9 \% \mathrm{Ni}$ and $\mathrm{Fe}-17 \% \mathrm{Mn}-3 \% \mathrm{Al}$ alloys) and $1130^{\circ} \mathrm{C}$ (for $\mathrm{Fe}-42 \% \mathrm{Ni}$ and $\mathrm{Fe}-24 \% \mathrm{Ni}-4 \% \mathrm{Mo}$ alloys). The cold wire drawing has been used for all the plastic deformation (except $5 \%$ deformation, which was done by authors [4] with the help of a tensile testing machine). TDIF measurements have been carried out on the inverted torsion pendulum at heating up to $600^{\circ} \mathrm{C}$ with the resonance frequency $\mathrm{f} \approx$ $1 \mathrm{~Hz}$ and the amplitude of deformation $\gamma \approx 10^{-5}$. Wire drawing has been used for the plastic deformation of different degree. 


\section{EXPERIMENTAL RESULTS}

The ADIF curves for Fe-25Ni-5Mo alloy is presented in Fig.1. The FR peak is observed only for alloys with $0.041 \% \mathrm{C}$ and more. Its height is proportional to carbon content in f.c.c. solid solution. This peak is broader than the Debye peak for a standard solid body. The broadening coefficient $\beta$ is about 2.6-3.5 for different carbon content. The plastic deformation leads to an increase in height of IF peak in the same temperatures range, where the FRP was observed before the deformation (Fig. 2). The height of this complex IF (DEFRP) peak increases with an increase in the degree of plastic deformation $\varepsilon, \%$. It should be noticed that quicker increase takes place in the alloy with higher carbon content (Fig. 2 b) than that in the alloy with lower carbon concentration (Fig. 2 a).
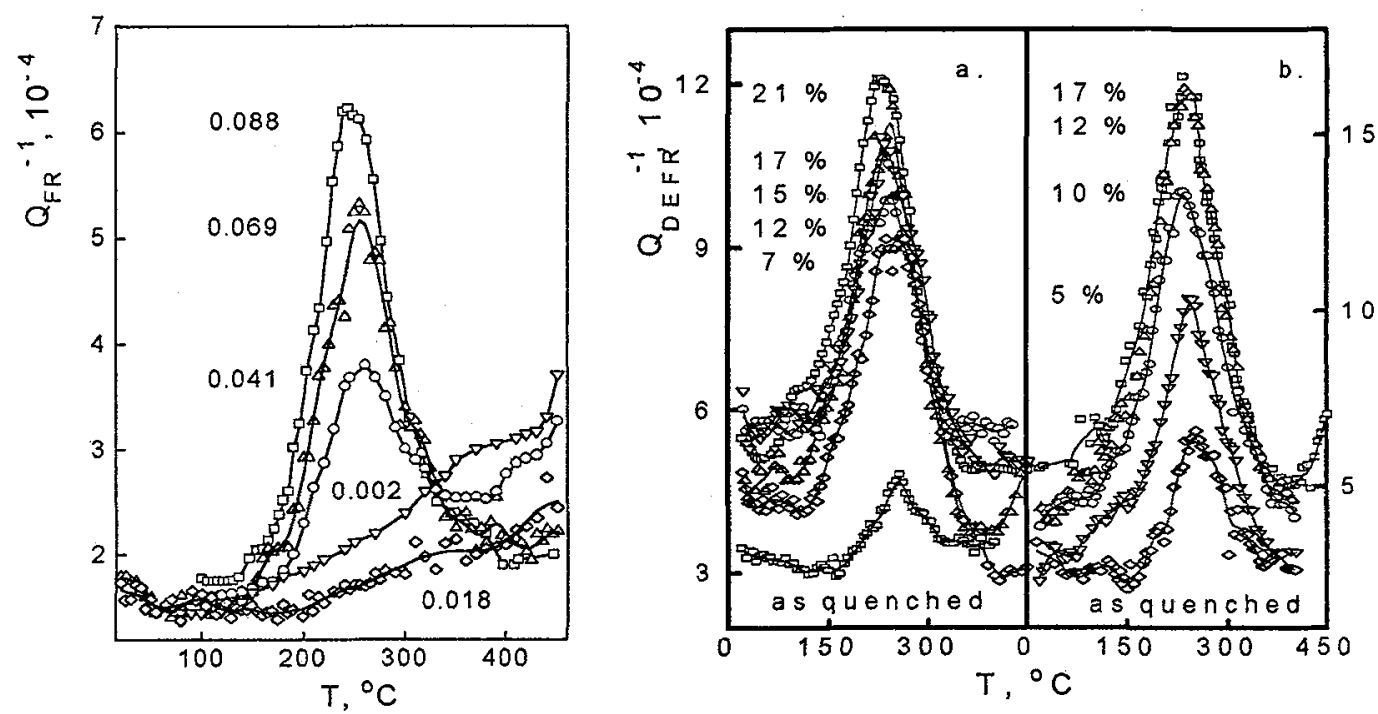

Figure 1. The influence of carbon content (digits near curves, in wt.\%) on height of the Finkelshtain-Rosin peak in $\mathrm{Fe}-(24.5-25.9) \% \mathrm{Ni}-(4.4-5) \% \mathrm{Mo}$ in quenched from $1150 \circ \mathrm{C}$ austenite.

Figure 2. The influence of plastic deformation degree on TDIF curves (initial state - water quenching from $1150 \circ \mathrm{C}$ ) $\mathrm{Fe}-25.9 \% \mathrm{Ni}-4.4 \% \mathrm{Mo}$ with $0.069 \% \mathrm{C}$ (a) and $0.088 \% \mathrm{C}$ (b). Digits near curves - deformation degree in $\%$.

Such a behaviour of DEFRP is common for different Fe-Ni and Fe-Mn based quenched and deformed austenitic steels (Fig. 3). Nevertheless, the slope of curve "height of DEFRP vs. the degree of plastic deformation" is different for different steels. First, the peak is smaller for the alloys with the lowest carbon content. The peak height is proportional to carbon content up to a certain concentration for the given strain degree [6] and is proportional to strain degree up to a certain deformation for the given carbon content. Secondly, in the Fe-Mn alloy this slope is not as high as it could be expected from the the highest carbon concentration in that alloy. The plastic deformation leads to the decrease of $M_{s}$, which is discussed in [7]. Finally, the DEFRP observed after deformation is not stable against ageing. The kinetics of a decrease in the height of the peak at $235^{\circ} \mathrm{C}$ is presented in Fig. 4. 

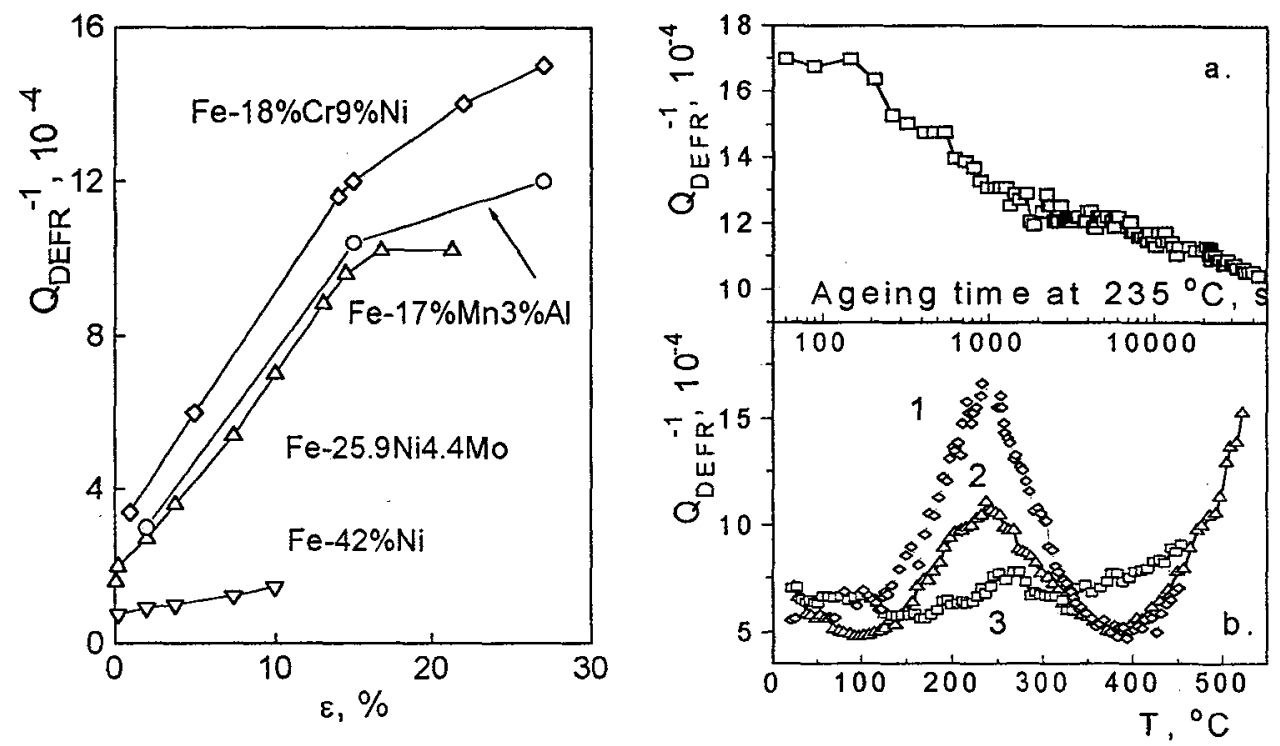

Figure 3. The influence of plastic deformation degree and chemical composition on the DEFRP height.

Figure 4. The height of DEFRP vs. ageing time at $235^{\circ} \mathrm{C}$ (a) and TDIF curves of water quenched austenitic alloy Fe25.9\%Ni4.4\%Mo-0.088\% $\%$ after 1) cold work $\varepsilon=17 \%$; 2) $1+$ ageing at $\left.235{ }^{\circ} \mathrm{C}, 12 \mathrm{~h} . ; 3\right) 1+$ ageing at $550{ }^{\circ} \mathrm{C}, 4 \mathrm{~h}$.

\section{DISCUSSION}

Following to [3], it should be pointed out that although the FR peak and the corresponding DEFRE peaks occur nearly at the same temperature, and the activation parameters of DEFRE are very similar to those of the FR effect, the DEFR peak is no longer a point defect relaxation. The DEFRE seems to be a common anelastic relaxation in Fe-Ni and Fe-Mn f.c.c. alloys containing interstitials similar to the Snoek-Ogurtani-Magalas (DESE) or the Snoek-Köster effects. The relaxation mechanism responsible for dislocation-enhanced impurity peak in austenite involves the $\mathrm{C}, \mathrm{N}$ atoms rearrangement in the stress field of a mobile screw and non-screw $\left(71^{\circ}\right)$ dislocation. Taking into account the low nitrogen content in alloys investigated we suppose that carbon atoms play the main role. The logarithmic decrement $(\delta)$ of impurities induced IF peak due to geometric kinks along the screw and nonscrew dislocations depends on the dislocation density of each type ( $\rho_{\mathrm{s}}$ and $\rho_{\mathrm{ns}}$ correspondingly) and the partial logarithmic decrements given by the screw and nonscrew dislocations $\left(\delta_{\mathrm{s}}\right.$ and $\delta_{\mathrm{ns}}$ correspondingly) as [3]: $\delta=\rho_{\mathrm{s}} \cdot \delta_{\mathrm{s}}+\rho_{\mathrm{ns}} \cdot \delta_{\mathrm{ns}}$. In pure iron non-screw (71) dislocation plays the most important role in the formation DESE [4] in b.c.c crystals. The reason for this is that at room temperature the mobility of screw dislocation is lower and the Peierls-Nabarro stress for screw dislocations is higher than that for nonscrew one. It is well known that the interaction of screw dislocations with impurities is much weaker than that of the nonscrew dislocations because a spherical distortion field around single atoms. That is why the term $\left(\rho_{s} \cdot \delta_{s}\right)$ is neglected in $[3,4]$. Contrary to the Snoek effect in b.c.c. metals correlated with the migration of separate interstitial atoms "C", "N", "O" in ferrite, the FR peak in austenite is due to the reorientation of pairs of interstitial atoms with low order of strain symmetry. That is why FRP is observed at $\mathrm{C}>\mathrm{C}_{\mathrm{cr}}(\sim 0.02 \mathrm{wt} \% \mathrm{C})$, only. So, tentatively the DEFRE/C is connected (i) with the motion of nonscrew dislocations through a interstitial and substitutional atmospheres - that statement fits for both b.c.c. and f.c.c. crystals with non-screw dislocations; and (ii) with the interaction of moveable screw dislocations with elastic distortions given by pairs of interstitial 
atoms - that is the peculiarity of dislocation interaction of screw dislocations with interstitials in f.c.c. steels with $\mathrm{C}>\mathrm{C}_{\mathrm{cr}}$. The energy of dislocation-impurity interaction in f.c.c. alloys depends on stacking fault energy. The salient features of the DEFRE in austenite studied in [6] and this paper are also similar to DESE in iron reported by Magalas [4] excluding point $\mathrm{N}^{\circ} 4$ :

1. The DEFRE/C occurs in freshly deformed Fe-Ni and Fe-Mn austenite (Fig. 2 and 4).

2. The DEFRE/C occurs at nearly the same temperature as the corresponding FR peak (Fig. 1, 2).

3. The relaxation strength of the DEFRE/C is proportional to the amount of plastic deformation at room temperature, i.e. to dislocation density (Fig. 2 and 3). Thus the responsible relaxation mechanism of DEFRE/C must involve the movement of dislocations.

4. Contrary to DESE, the enhancement of the FR peak due to a plastic deformation is stronger for higher concentration of interstitials (Fig. 2). The DEFRE is stronger in $\mathrm{Fe}-\mathrm{Cr}-\mathrm{Ni}, \mathrm{Fe}-\mathrm{Ni}-\mathrm{Mo}$ and $\mathrm{Fe}-\mathrm{Mn}-\mathrm{Al}$ than in Fe-Ni austenite (Fig. 3).

5. The DEFRE/C is a metastable relaxation. The thermal instability of the DEFRE/C is due to dislocation pinning by interstitials (Fig. 4).

Obviously, some quantitative differences between $\operatorname{DESE}[2,3]$ and DEFRE (e.g. see the above point 4) appear due to (i) the different solubility of interstitials in b.c.c. and f.c.c. solid solutions, (ii) differences in the dislocation and dislocation core structures, density and mobility of screw and non-screw dislocation in austenite and ferrite, (iii) the different dependence and mechanism of the Snoek (single atoms) and the FR (atom pairs) peaks height on impurity content and (iv) the influence of substitutional atoms on interstitials distribution. It is well known that stacking fault energy in Fe-Mn austenite is lower than that is in Fe-Ni one. This fact determines the weaker dislocation-impurities interaction and higher strain hardening, and, in particular, to the weaker slope of DEFRP vs. strain degree. Contrary to Fe-Mn based austenite in Fe-Ni based austenite the sell structure is observed after deformation. Further work on quantitative differences between DEFRE in Fe-Ni and Fe-Mn and DESE in Fe is in progress and will be reported later. Finally, the experimental results obtained in this study show that the observed anelastic relaxation is carbon Dislocation-Enhanced Finkelshtain-Rosin Effect - DEFRE/C.

\section{CONCLUSIONS}

Summarizing the experimental results we believe that the peak in deformed austenite with the new anelastic mechanism - carbon Dislocation-Enhanced Finkelshtain-Rosin Effect has been found. This DEFR effect is similar to the DES effect in deformed ferrite, reported in $[2,3]$. The plastic deformation at room temperature causes a transformation of FR peak into a DEFRP/C occurring at nearly the same temperature. The DEFRP is due to a movement of non-screw dislocations controlled by the relaxation of interstitial atoms, in addition to the similar DESP in iron, we suppose that the interaction of the screw dislocations with distortions given by pairs of interstitial atoms in austenite gives additional component of the damping $\left(\rho_{s} \cdot \delta_{s}\right)$. This term was reasonably neglected for the explanation of DESE in b.c.c. crystals [4] but is important in f.c.c. alloys. The instability of the DEFRE/C are explained by the diffusion of interstitials and dislocation pinning.

\section{References.}

1. Rosin K.M., Finkelshtain B.N. Dokl. AN SSSR, 1953, 291, 4, p. 811.

2. De Batist R. Mechanical Spectroscopy. Materials Sci. and Techn., vol.2B, VCH, 1994, p.159-217.

3. Ogurtani T.O., Seeger A.K. Phys. Rev. B., vol. 31, N. 8, p. 5044.

4. Rubianes J., Magalas L.B., Fantozzi G., San Juan J.. J.de Physique, C.8, 1987, sup. n. 12, T. 48, p. 185.

5. Golovin S.A., Belkin K.N. Phys. Met. \& Metallogr., 1965, vol.2, N 5, p.763.

6. Golovin I., Zharkov R., Golovin S.A. Proc. of "Mechanics and Mechanisms of Material Damping" Symposium, November 15-17, 1995, Norfolk, Virginia, USA, to be published.

7. Golovin I., Goncharov S., Golovin S.A. The contribution of dislocation-impurities interaction to kinetics of martensitic transformation of quenched f.c.c. Fe-Ni-Mo alloys. This Conference. 